\title{
Hampshire Pig
}

National Cancer Institute

\section{Source}

National Cancer Institute. Hampshire Pig. NCI Thesaurus. Code C77103.

One of the oldest orig inal early American pig strains, the Hampshire pig orig inated from the Old Eng lish breed and was imported to North American in the mid-1800s. The Hampshire pig has black skin and hair covering most of its body with a white portion of skin covering its front limbs and back. The Hampshire pig is one of the larger pig breeds used in biomedical research. 